\title{
Key descriptors and level of intercultural competence of the future fashion designers
}

\author{
K. Ryabchikova, T. Popova, S. Nechipor \\ Ukrainian Engineering Pedagogic Academy, Kharkov, Ukraine
Corresponding author. E-mail: tpopovauipa@gmail.com
}

Paper received 04.09.18; Accepted for publication 09.09.18.

https://doi.org/10.31174/SEND-PP2018-175VI73-07

\begin{abstract}
An algorithm for complex assessment of intercultural competency of specialists in the field of fashion design is developed on the basis of a comprehensive approach to the structure of competence, analysis of the levels of intercultural competence formation, taking into account possible forms and methods of teaching in the process of its formation. The article analyzes the structure of competence based on the use of modern approaches and recommendations of the European Commission on Education.

Keyword: intercultural competence, Dublin descriptors, communicative, cultural intelligence, fashion design
\end{abstract}

Introduction. Expansion of the sphere of training of fashion designers in the system of higher education of Ukraine testifies, in particular, of the re-orientation toward the humanization and humanization of education. Unfortunately, Ukraine still does not have strong traditions of training specialists in this field. At the same time, it makes it possible to effectively use the assets of the traditionally developed countries and universities in this area.

The transition to a competent system of training specialists allows universalizing the general approaches to the education of specialists - fashion designers at the same time as the development of their own ethno-cultural competencies.

The development of a competence approach poses two problems in the process of education of fashion designers. The first problem is related to the boundary between the universal international approaches to the training of specialists and the country's special needs. At the same time, today there are high requirements for the mobility of students and specialists who, in many cases, want to apply their competencies in other countries or cultures. The requirements for the effectiveness of international mobility are the need to introduce into a common system of competences of specialist in the fashion design special competences related to international and intercultural exchanges. In foreign publications in recent years, the problem of developing intercultural competency, which represents a complex of communicative, general cultural and special cultural abilities that allow a specialist to work in conditions of another culture, is widely discussed in this connection. Unfortunately, in Ukraine, the problems of developing intercultural competency have been little attention.

The second general problem of a competent approach, in our opinion is the lack of certainty of the possibility of verifying the achievement by a person of a certain level of competence. Considering that the competence of the Dublin Descriptors [1] is interpreted as a set of knowledge, skills, communication, autonomy and responsibility, the question arises of measuring these components. If certain approaches are developed to measure knowledge and skills, the process of measuring other components remains uncertain.

Problems of forming competencies of future fashion designers have been reflected in a number of publications. In most of them, the integral competence of designers of clothing is treated as a set of professional technical and artistic competencies. The methods of determining the formation of these competencies are determined.

The article [2] discusses the process of forming competencies for fashion designer in a context of rapid changes in technology and public life. The process of introducing new professional competencies into the system of training specialists - designers of clothing is considered.

The set of publications is devoted to the question of the formation of intercultural competence. A number of them directly explore the formation of intercultural competence among designers. In the work [3], for example the study of the role of cultural orientation in improving intercultural competence in multicultural organizations in the direction of design present, in the work [4] a short algorithm for the operation of designers working on beyond its cultural boundaries is developed.

The problem of creating intercultural competence by domestic researchers was solved only fragmentarily. Intercultural competency is considered from the point of view of the success of the educational process as a whole or the task of taking into account the cultural peculiarities in the process of teaching of certain pieces of art specialty of fashion design.

In scientific sources, the complexity of determining the components of intercultural competence and the methods for assessing their formation are noted.

In the work [5] it is noted that cultural competence is the basic requirement of a person for effective work with representatives of different cultures. However, there is no consensus on the definition or components of this concept, and there is a lack of empirical evidence that points to the benefits of cultural competence. Therefore, a systematic review was carried out to determine the most common criteria of competence in the field of culture.

The paper [6] presents the results of a mixed method study which purpose is to measure the intercultural development of students and their perception of intercultural learning in academic settings.

China's researchers have probably made the greatest progress in measuring cross-cultural competence. The paper [7] noted that in order to satisfy a large empirical interest in competence and sensitivity to intercultural communication, it is necessary to study the measures for measuring intercultural sensitivity for use in contexts with constraints.

The study [8] uses methods of modeling structural 
components and constructing a scale for measuring intercultural communication between students and studying the ways of intercultural communication for the formation of intercultural competency with the definition of their significance levels.

The aim of this work is to develop a method of integrated assessment of the intercultural competence of specialists in the field of fashion design based on an integrated approach to the structure of competence, analysis of levels of intercultural competence formation, consideration of possible forms and teaching methods in the process of its formation.

Methods. The Dublin Competency Structure consists of harmonious knowledge, skills, communication, autonomy and accountability. Structural elements of competence determine the achievement of a certain level of theoretical training, the development of abilities to the practical implementation of a particular work, the search for information to improve the identified issue, work independently and in the team, responsibility for decisionmaking, obtaining incentives or reprimands.

In such a statement the definition of the level of the formation of intercultural competence is logically seen as a summary assessment of the student's achievement of its individual components. At the same time it is necessary to consider the methods of measurement and evaluation, as well as specific for this competence abilities and actions.

General theory of measuring of the content and level of knowledge, as well as methods for measuring knowledge as a part of competencies is considered in many studies. A slightly different approach is shown to measurement of the level of development of abilities. World Organization OECD regularly conducts measurement of knowledge and skills by testing methods. In real enterprises, more common methods are used to determine the differences between the necessary skills to perform certain work and the actual state of their formation. Unfortunately, in many cases, qualitative indicators that are difficult to measure are used to assess the levels of skill development. Fragmentary information on measuring the next component of competence - communication can only be found in a few articles, and they are often treated only as communicative skills.

As for the methods of measuring of such competencies as autonomy and responsibility, there are practically no researches in these areas.

Let us now dwell on the specific competencies we explore - intercultural competence. Obviously, in addition to the above-mentioned structural components, it must include its own levels, or components of the formation.

Most researchers distinguish a communicative component in the intercultural competence which level is largely determined by the level of proficiency in a foreign language. Without denying the importance of this component, we emphasize that, firstly, not all of its components are yet to be measured, and secondly, the linguistic component is not such that fully determines intercultural competence.

In the international pedagogical works devoted to the development of intercultural competence, the concept of intercultural intelligence becomes increasingly popular. The acquisition of intercultural competence, according to the authors of these studies, suggests as an essential ele- ment in the formation of a certain level of cultural intelligence. It is believed that for cultural intelligence, the concept of motivation for intercultural development is very important.

Some papers prove the necessity of the formation of cultural intelligence for the so-called planetary education of student youth. We believe that planetary education is quite close to the concept of intercultural competence, although unlike it, planetary education may not need to be measured, since it is not a compulsory part of the professional program of fashion designer. Special courses for the formation of cultural intelligence should form the imperative of self-knowledge, while emphasizing their own cultural identity and parallels other cultural identities in order to build their own intercultural competence.

The highest level of intercultural competency formation is the especially professional level that relates to the formation of intercultural competencies. At the stage of knowledge formation, this component of competence can be ensured through the introduction of special courses that provide knowledge about fashion design in different countries or in different cultures. These may be special intercultural disciplines or sections in the curriculum of disciplines that form a special professional competence.

In our opinion, the formation of practical skills for specialists in fashion design should be ensured in two main ways. The first way is practice, foreign internships, studies within academic mobility. The main practical direction of formation of intercultural professional competencies should be educational intercultural projects of collections of clothing, performed in the form of international student collectives. The experience of the organization of such international student teams is described in a number of foreign publications.

Intercultural project skills in the implementation of such projects necessarily include a communicative component, as the progress of the project should be regularly discussed in the mode of e-mail correspondence, as well as the regular conduct of online conferences between student teams of two or more universities and countries . Modern technical equipment allows to provide such interconnecting conference in special auditoriums or personally using modern means of communication with the use of specialized programs Skipe, Viber, WhatsApp. The role of the teacher at the same time increases, because in addition to the general management of the project, he must act as the coordinator of student communication, have independent skills in intercultural communication, fluent in foreign language.

Results. The conducted analysis of descriptors for the formation of intercultural competency of fashion designers allowed to construct a general model for measuring its level (see table). Such a model represents a twodimensional matrix of descriptors. One direction corresponds to the formation of competence in terms of Dublin descriptors - knowledge, skills, communication, autonomy and responsibility.

The second line corresponds to the levels of intercultural competency formation for fashion designers. It includes a communicative component that is mainly related to the ability to communicate with representatives of another country or culture and includes mandatory requirements for the knowledge and ability to use a foreign 
language. The next component of this direction is the formation of the cultural intelligence of a person as a specialist who can work in other cultures without losing his or her own cultural identity. A professional component of intercultural competence is responsible for taking cultural features into account in the design, production and implementation of clothing models.

At the same time, each component of intercultural competence must go through stages and levels relative to the Dublin descriptors.

Discussion. Linguistic communicative component of intercultural competence at the stage of formation of knowledge should include a certain vocabulary, basic linguistic rules and turns. Since the standard language for intercultural communication is English, it would be desirable to have knowledge in this direction. In the case of the desirability of forming intercultural competence in the conditions of the prospects of work in a particular country, a condition for knowledge of its national language may be added. Methods for evaluating this component are widely known and may include testing, current evaluation and other control measures.

The level of skill for this component should take into account the ability to communicate with a representative of another country or culture. In our opinion, in the conditions of the formation of intercultural competence for the formation of this skill, it is insufficient traditional training in national audiences. Basic skills of intercultural communication should be manifested in the conditions of foreign communication. This level can be achieved by using virtual communication, conducting online meetings with foreign students, conducting foreign linguistic practices. The criterion and indicator for measuring this component may be the level of understanding of a foreign language, for example, the percentage of comprehensible material.

In the process of evaluating the component of communication, the level of discussion of problems in the process of Internet conferences or in practice and internship should be taken into account. Problems can be discussed in the simplest, problems related to complex concepts, professional problems. According to the level of the raised problems the assessment of the component of communication of general intercultural competence increases.

The components of autonomy and responsibility in the formation of intercultural competence determine the possibility of self-improvement and may include the use of language elements of the other party or country (if different from English) with an appropriate evaluation of the results.

The process of forming and measuring the components of intercultural competence at the stage of intercultural intelligence should also include the components of the Dublin descriptors.

Component knowledge is provided by studying special courses or sections in traditional courses that take into account the peculiarities of the culture of different countries and peoples (Courses "History of Culture", "History of Art") using traditional methods of assessment (testing, current evaluation, etc.).

The level of ability of a component of cultural intelligence is determined by the ability to orient in cultural features in other countries. A form of checking the level of formation of this component can be represent as virtual tasks for behavior, taking into account cultural characteristics or practical situations during practice.

Table 1. Levels of intercultural competence of fashion designers

\begin{tabular}{|c|c|c|c|c|}
\hline $\begin{array}{c}\text { Components of } \\
\text { interculturalism }\end{array}$ & Knowledge & Ability & Communications & $\begin{array}{c}\text { Autonomy and responsi- } \\
\text { bility }\end{array}$ \\
\hline $\begin{array}{c}\text { Linguistic } \\
\text { component }\end{array}$ & $\begin{array}{c}\text { Basic linguistic } \\
\text { rules/ }\end{array}$ & $\begin{array}{c}\text { Ability to conduct a } \\
\text { conversation in a foreign } \\
\text { language }\end{array}$ & $\begin{array}{c}\text { The level of discussion of } \\
\text { problems in the process of } \\
\text { Internet conferences or dur- } \\
\text { ing practice and internships }\end{array}$ & $\begin{array}{c}\text { Use language elements of } \\
\text { the other party or country } \\
\text { (if different from English) }\end{array}$ \\
\hline $\begin{array}{c}\text { Intercultural } \\
\text { intelligence }\end{array}$ & $\begin{array}{c}\text { Features of the } \\
\text { culture of } \\
\text { different coun- } \\
\text { tries }\end{array}$ & $\begin{array}{c}\text { Orientation in the peculi- } \\
\text { arities of cultural behav- } \\
\text { ior in other countries }\end{array}$ & $\begin{array}{c}\text { Discussions in the process of } \\
\text { Internet conferences (practice } \\
\text { or internships) of cultural } \\
\text { characteristics of countries }\end{array}$ & $\begin{array}{c}\text { The introduction of ele- } \\
\text { ments of culture of the } \\
\text { second party or culture } \\
\text { into cultural events or } \\
\text { methodical materials }\end{array}$ \\
\hline $\begin{array}{c}\text { Intercultural } \\
\text { features of } \\
\text { fashion design }\end{array}$ & $\begin{array}{c}\text { Features of } \\
\text { clothes of } \\
\text { different coun- } \\
\text { tries and peo- } \\
\text { ples }\end{array}$ & $\begin{array}{c}\text { Ability to develop clothes } \\
\text { designs for another coun- } \\
\text { try, taking into account } \\
\text { the peculiarities of anoth- } \\
\text { er culture }\end{array}$ & $\begin{array}{c}\text { Participation in a joint project } \\
\text { for the development of an } \\
\text { international garment collec- } \\
\text { tion, taking into account } \\
\text { intercultural features. }\end{array}$ & $\begin{array}{c}\text { Implementation of the } \\
\text { results of the project in } \\
\text { real offers or methodo- } \\
\text { logical materials }\end{array}$ \\
\hline
\end{tabular}

The component of communication at the stage of the formation of cultural intelligence can be formed during the discussion on Internet conferences (practices or internships) of cultural features of two or more cultures or countries. An indicator of the formation of this component should be the level of assimilation of cultural characteristics. In our opinion, this indicator should be evaluated by the students of the opposite side. This assessment method, in addition to objectivity, will carry the function of increasing the cultural identity itself and correspondingly increasing its own cultural intelligence.

The component of autonomy and responsibility in the formation of cultural intelligence can be determined by the introduction of elements of culture of the second party or implementation in cultural events or methodological materials. This component can be evaluated by the level of implementation and can be determined when discussing the participants of both parties in the process of online conferences.

The use of components of the Dublin descriptors to form and evaluate the intercultural professional fashion design can give the following results.

The component of knowledge determines the peculiarities of clothes of different countries and peoples (courses 
"History of fashion", "Theory of design", sections in special courses) and evaluated by traditional means.

Component skills determine the ability to design clothing projects for another country, taking into account the characteristics of another culture. At this stage, in our opinion, the project may be internal in nature, guided and evaluated by an expert in own part or culture, which has intercultural competencies in this field.

Component skills determine the ability to design clothing projects for another country, taking into account the characteristics of another culture. At this stage, in our opinion, the project may be internal in nature, guided and evaluated by an expert on its part or culture, which has intercultural competencies in this field.

The component of communication at this stage should involve participation in a joint project for the development of an international collection of clothing, taking into account intercultural features. In order to determine the level of formation of this stage, an assessment of the finished project and the port of a folio are carried out by a group of experts representing the parties (countries) of the international project.

The component of autonomy and responsibility is taken into account by research of the implementation of the results of the project in real realizations or methodological materials. At the same time, the highest level of imple- mentation, in our opinion, is the commercial realization of a collection of clothing, performed in the process of developing an international intercultural project. The level of implementation should be evaluated by experts from both sides.

After evaluating of each component of the intercultural competence of a specialist in the field fashion design, one can determine the general level of its formation.

Conclusions. The method of complex assessment of the intercultural competence of specialists in the field of fashion design is developed on the basis of a comprehensive approach to the structure of competence, analysis of levels of intercultural competence formation, taking into account possible forms and methods of teaching in the process of its formation. The process of formation and evaluation of intercultural competence is presented in the form of a two-dimensional matrix and takes into account one direction of the formation of components of Dublin descriptors at another level of intercultural competence language communicative competence, cultural intelligence, intercultural competence.

The introduction of this technique will explicitly determine the levels of formation of individual components of intercultural competence and measure the overall level of intercultural competence of a specialist in the field of design of clothing.

\section{REFERENCES}

1. ECTS Users' Guide, European Union, (2015), 109pp. 5. Alizadeh S., Chavan M. (2016) Cultural competence dimenhttp://ec.europa.eu/education/ects/users-guide/docs/ectsusers-guide_en.pdf

2. Ryabchykova K. (2016) Dynamic curriculum for the extrapolation of innovative texhnologies in fashion. Problemi inzhenerno-pedagogichnoyi osviti [Problems of engineering and pedagogical education] № 52-53, pp.143-151

3. Dias D., Zhu C.J., Samaratunge R. (2017) Examining the role of cultural exposure in improving intercultural competence: implications for HRM practices in multicultural organizations. International Journal of Human Resource Management, pp. 1-20

4. Melissa McMullen (2016) Intercultural design competence: A guide for graphic designers working across cultural boundaries. International Journal of Visual Design, 10(3), pp. 19-30 sions and outcomes: a systematic review of the literature. Health and Social Care in the Community, 24(6), pp. e117e130

6. Garson K.D. (2016) Internationalization and intercultural learning: A mixed methods study. Promoting Intercultural Communication Competencies in Higher Education pp. 54-88

7. Wang W., Zhou M. (2016) Validation of the short form of the intercultural sensitivity scale. (ISS-15) International Journal of Intercultural Relations 55, pp. 1-7

8. Peng R.-Z., Wu W.-P. (2016) Measuring intercultural contact and its effects on intercultural competence: A structural equation modeling approach. International Journal of Intercultural Relations 53, pp. 16-27 